\title{
Damage of Poaceae plants caused by slugs from the genus Deroceras and Arion
}

\section{Uszkodzenia roślin Poaceae przez ślimaki rodzaju Deroceras i Arion}

Monika Jaskulska ${ }^{1 *}$, Jan Kozłowski ${ }^{1}$, Maria Kozłowska²

\section{Summary}

Grasses (Poaceae Barnh.) are damaged by many pest species, including slugs, especially by slugs from the genus Deroceras and Arion. These animals feed on seeds and green plant material near the surface of the ground and show a clear selectivity towards individual species, cultivars or forms of plants. So far, little research has been done on the food preferences of snails feeding on grass plants. In these studies, plants from five grass meadow and wheat (Triticum aestivum L.) species were exposed to Deroceras reticulatum (O. F. Müller, 1774) and Arion vulgaris Moquin-Tandon, 1855 feeding under laboratory conditions. There was a different variation in the magnitude of plant damage depending on the plant species and slug species. Higher susceptibility to damage was demonstrated by plants Poa pratensis and Festuca rubra contrary to plants Bromus wildenowii, Festulolium, Lolium multiflorum and Triticum aestivum.

Key words: slugs, grasses, damage

\section{Streszczenie}

Trawy (Poaceae Barnh.) są uszkadzane przez różne gatunki agrofagów w tym także przez ślimaki, zwłaszcza przez ślimaki nagie z rodzaju Deroceras i Arion. Zwierzęta te żerują na nasionach i zielonym materiale roślinnym w pobliżu powierzchni gruntu i wykazują wyraźną selektywność w stosunku do poszczególnych gatunków, odmian lub form roślin. Dotychczas wykonano niewiele badań dotyczących preferencji pokarmowej ślimaków żerujących na roślinach traw. W tych badaniach, w warunkach laboratoryjnych eksponowano rośliny pięciu gatunków traw łąkowych i pszenicy zwyczajnej (Triticum aestivum L.) na żerowanie ślimaków Deroceras reticulatum (O. F. Müller, 1774) i Arion vulgaris Moquin-Tandon, 1855. Stwierdzono zróżnicowanie w wielkościach uszkodzeń roślin w zależności od gatunku rośliny i gatunku ślimaka. Wyższą podatność na uszkodzenia przez ślimaki wykazały rośliny Poa pratensis i Festuca rubra niż rośliny Bromus wildenowii, Festulolium, Lolium multiflorum i Triticum aestivum.

Słowa kluczowe: ślimaki, trawy, uszkodzenia

\footnotetext{
${ }^{1}$ Instytut Ochrony Roślin - Państwowy Instytut Badawczy

Zakład Entomologii i Agrofagów Zwierzęcych

Władysława Węgorka 20, 60-318 Poznan

2 Uniwersytet Przyrodniczy w Poznaniu

Katedra Metod Matematycznych i Statystycznych

Wojska Polskiego 28, 60-637 Poznań

*corresponding author: m.jaskulska@iorpib.poznan.pl

ORCID: 0000-0001-6212-0479
} 


\section{Wstęp / Introduction}

Ślimaki nagie (Gastropoda: Agriolimacidae i Arionidae) uszkadzają wiele gatunków roślin rolniczych i warzyw, a wśród nich niektóre gatunki uprawianych lub dziko rosnących traw (South 1992; Glen i Moens 2002; Barlow i wsp. 2013). Stopień ich uszkodzenia jest zróżnicowany, co wynika z różnych preferencji pokarmowych ślimaków oraz specyficznych właściwości gatunków i odmian roślin (Briner i Frank 1998; Keller i wsp. 1999; Kozłowski i Kozłowska 2009). Ślimaki niszczą nasiona traw, bezpośrednio po wysiewie lub podczas kiełkowania, uniemożliwiając wschody roślin. Po wschodach, żerują na siewkach powodując często całkowite ich zniszczenie. Młode rośliny są szczególnie wrażliwe na uszkodzenia (Glen i Moens 2002). Ślimaki zdrapują tkanki roślinne i wygryzają w nich otwory, powodując charakterystyczne strzępienie liści. Takie rośliny są osłabione, a niektóre pozbawione dużej powierzchni tkanek wysychają i giną. Rośliny są niszczone w wielu miejscach pól, co często powoduje niecelowość dalszej uprawy. Jednak, jeśli rośliny rosną szybko, to mogą tolerować umiarkowany poziom zgryzania przez ślimaki. Dojrzałe rośliny traw są mniej narażone na uszkodzenia (Dirzo 1980). Jednak w przypadku niektórych traw, na przykład pszenicy zwyczajnej (Triticum aestivum L.), ślimaki mogą niszczyć liście flagowe dojrzałych roślin, co prowadzi niekiedy do redukcji plonu (Kemp i Newell 1987). Obok rzepaku, pszenica zwyczajna jest najważniejszą rośliną uprawną zagrożoną przez ślimaki w środkowej oraz zachodniej Europie i wymaga ochrony przed tymi szkodnikami (Glen i Moens 2002). W ostatnich latach, coraz częściej obserwuje się szkody wyrządzane przez ślimaki w uprawach traw łąkowych. Głównymi sprawcami szkód są: najbardziej rozpowszechniony na polach uprawnych pomrowik plamisty - Deroceras reticulatum (Agriolimacidae) oraz gatunek inwazyjny ślinik pospolity - Arion vulgaris (Arionidae).

Celem przeprowadzonych badań było ustalenie podatności siewek wybranych gatunków traw na uszkodzenia przez te dwa gatunki ślimaków.

\section{Materiały i metody / Materials and methods}

Rośliny kostrzewy czerwonej (Festuca rubra L.) odmiany Areta, stokłosy uniolowatej (Bromus wildenowii Kunth) odmiany Jeronimo, życicy wielokwiatowej (Lolium multiflorum Lam.) odmiany Mitos, wiechliny łąkowej (Poa pratensis L.) odmiany Oxford, kostrzycy (Festulolium sp.) odmiany Spring Green oraz pszenicy zwyczajnej (Triticum aestivum L.) odmiany Arkadia eksponowano na żerowanie ślimaków $D$. reticulatum i A. vulgaris. Ślimaki do doświadczeń zebrano z upraw ogrodniczych z okolic Poznania.
Rośliny w fazie 3-4 liści, które wyhodowano w szklarni, w Instytucie Ochrony Roślin - Państwowym Instytucie Badawczym, posadzono w ziemi w zamykanych pojemnikach $(26 \times 26 \times 14 \mathrm{~cm})$, po pięć roślin jednego gatunku w pojemniku. Po dwóch dniach w pojemnikach umieszczono po jednym wygłodzonym przez 48 godzin ślimaku o średniej masie: $D$. reticulatum $-0,92 \pm 0,17 \mathrm{~g}$ i A. vulgaris $-1,52 \pm 0,05$ g. Doświadczenia wykonano w kabinie klimatycznej, w temperaturze powietrza $17^{\circ} \mathrm{C}$, RH $70 \pm 3 \%$ i długości dnia 12 godzin. Przez dziewięć dni, raz dziennie oceniano uszkodzenia roślin według 5-stopniowej skali $(0,25,50,75$ i 100\% uszkodzonej powierzchni roślin) i wyznaczano średnią dla pięciu roślin w pojemniku. Wykonano sześć powtórzeń (6 pojemników po 5 roślin) dla każdego gatunku rośliny i ślimaka. Uzyskane wyniki dotyczące $A$. vulgaris poddano analizie wariancji ANOVA i zastosowano procedurę Fishera przy poziomie istotności $\alpha=0,05$. W przypadku $D$. reticulatum, ze względu na niejednorodność wariancji, zastosowano nieparametryczny test Kruskala-Wallisa i test wielokrotny do porównania średnich przy $\alpha=0,05$ (STATISTICA V. 13).

\section{Wyniki i dyskusja / Results and discussion}

Pierwsze istotne różnice $\mathrm{w}$ wielkościach uszkodzeń roślin przez $D$. reticulatum wystąpiły po trzech dniach żerowania ślimaków (tab. 1). Istotnie silniej uszkodzone były rośliny wiechliny łąkowej $(66,7 \%)$ w porównaniu do roślin pszenicy zwyczajnej $(23,3 \%)$. Obok roślin wiechliny łąkowej, która po siedmiu dniach została uszkodzona w $100 \%$, silniej uszkadzane były także rośliny kostrzycy. W ostatnim dniu obserwacji, istotnie silniej uszkodzone były rośliny wiechliny łąkowej (100\%) i kostrzycy $(97,5 \%)$, a najsłabiej rośliny pszenicy zwyczajnej $(66,7 \%)$.

Arion vulgaris, po czterech dniach żerowania, istotnie silniej uszkodził rośliny kostrzewy czerwonej (32,5\%) niż wiechliny łąkowej (15\%). Od szóstego do ostatniego, dziewiątego dnia żerowania ślimaków, istotnie słabiej uszkadzane w porównaniu do roślin kostrzewy czerwonej były rośliny życicy wielokwiatowej i pszenicy zwyczajnej (tab. 2). Po dziewięciu dniach najsilniej uszkodzone były rośliny kostrzewy czerwonej $(63,3 \%)$, a najsłabiej rośliny pszenicy zwyczajnej $(33,3 \%)$ i życicy wielokwiatowej $(36,7 \%)$.

W wyniku przeprowadzonych badań stwierdzono, że silniej uszkadzane przez $D$. reticulatum były rośliny wiechliny łąkowej, a przez A. vulgaris rośliny kostrzewy czerwonej. Natomiast słabo uszkadzane przez obydwa gatunki ślimaków były rośliny pszenicy zwyczajnej. Ponadto stosunkowo słabo uszkadzane przez $A$. vulgaris były także rośliny wiechliny łąkowej i życicy wielokwiatowej.

Najwięcej informacji na temat stopnia uszkodzenia traw przez ślimaki i metod ich ochrony przed skutkami żerowania 

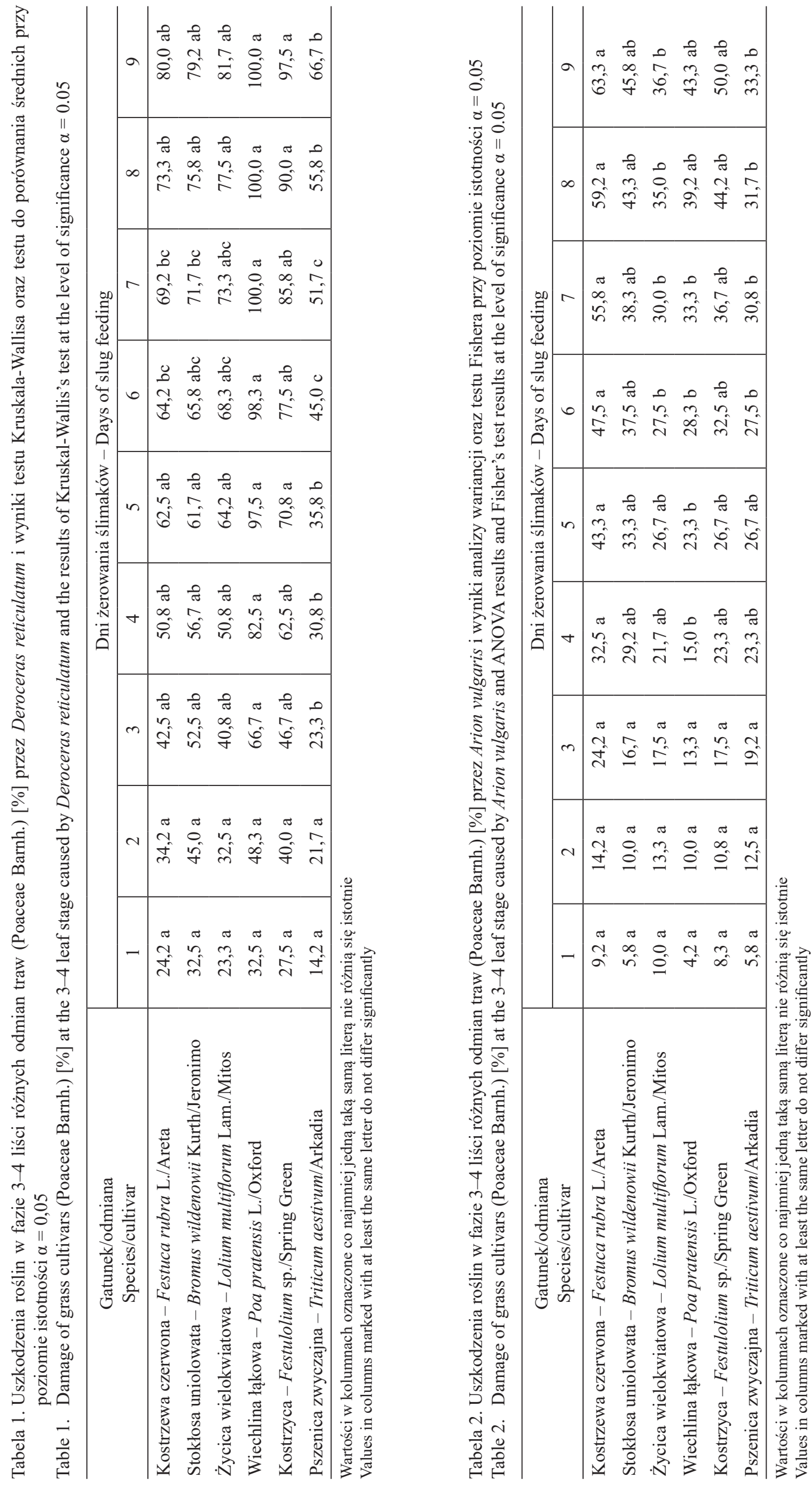
tych szkodników dotyczy pszenicy ozimej (Glen i Moens 2002). Znacznie słabiej pod tym względem są poznane pozostałe trawy, szczególnie trawy łąkowe. Przeprowadzone badania dostarczają brakujących danych na temat uszkodzeń roślin kostrzewy czerwonej, kostrzycy, stokłosy uniolowatej, wiechliny łąkowej i życicy wielokwiatowej w porównaniu do uszkodzeń roślin pszenicy ozimej (tab. 1, 2). Wiadomo, że pszenica zwyczajna (zwłaszcza jej formy ozime), jest najczęściej i najsilniej uszkadzaną przez ślimaki rośliną spośród traw zbożowych (South 1992; Glen i Moens 2002). Podobnie, jak w przypadku innych traw ślimaki zjadają zarodki i bielmo nasion oraz siewki po wschodach, co powoduje znaczny spadek plonu. Starsze rośliny są mniej narażone na uszkodzenia (Kozłowski i Kozłowska 2009). Inne rośliny zbożowe, takie jak jęczmień zwyczajny (Hordeum vulgare L.) i owies zwyczajny (Avena sativa L.) są podobnie uszkadzane, jednak poziom ich uszkodzeń jest znacznie mniejszy niż upraw pszenicy zwyczajnej, która jest rośliną preferowaną przez ślimaki.

Wrażliwość poszczególnych gatunków i odmian traw na uszkodzenia przez ślimaki wynika $\mathrm{z}$ różnic $\mathrm{w}$ budowie fizycznej roślin oraz $\mathrm{z}$ różnic $\mathrm{w}$ poziomie zawartości składników chemicznych (Keller i wsp. 1999). Ślimaki są zwykle zniechęcone żerowaniem przez twardą teksturę liści (Grime i wsp. 1968; Hanley i wsp. 2007) i metabolity wtórne, takie jak taniny, związki fenolowe, flawonoidy, alkaloidy, glikozydy, saponiny i inne (Dirzo i Harper 1982; Mølgaard 1986; Speiser i Rowell-Rahier 1991; Hanley i wsp. 1995; Clark i wsp. 1997). Duży wpływ na stopień uszkodzenia traw mają także substancje silikonowe, takie jak krzemionki. Stężenia tych substancji w roślinach są zróżnicowane i w przypadku siewek niektórych gatunków lub odmian traw mogą być skutecznymi deterentami dla ślimaków, które chronią rośliny przed ich żerowaniem (Grime i wsp. 1968; Dirzo 1980; Hanley i wsp. 2004; Barlow i wsp. 2013). U większości traw wraz ze starzeniem się roślin wzrasta zawartość substancji silikonowych, które powodują, że liście stają się sztywne i twarde, a tym samym nie są już chętnie zjadane przez ślimaki.

Przedstawione badania wskazują, że poziom uszkodzeń badanych gatunków traw łąkowych przez ślimaki $D$. reticulatum i A. vulgaris jest znacznie wyższy w porównaniu do roślin pszenicy zwyczajnej. Dotyczy to zwłaszcza wiechliny łąkowej, która okazała się bardziej wrażliwa na żerowanie $D$. reticulatum oraz kostrzewy czerwonej bardziej wrażliwej na żerowanie $A$. vulgaris. Według Barlow i wsp. (2013), którzy badali w warunkach laboratoryjnych poziom uszkodzeń siewek 23 gatunków roślin łąkowych, wysoki poziom uszkodzeń przez $D$. reticulatum wykazały kostrzewa czerwona i wiechlina zwyczajna (Poa trivialis L.), natomiast życica trwała (Lolium perenne L.) była rośliną słabo uszkadzaną przez tego ślimaka. South (1992) podaje, że kostrzewa łąkowa (Festuca pratensis Hud.) wysiewana $\mathrm{w}$ jęczmieniu jest rośliną silnie uszkadzaną przez ślimaki. Przytoczone wyniki wskazują, że trawy z rodzaju Festuca i Poa są preferowane przez ślimaki. Jednak nie w przypadku, gdy rośliny należące do tych rodzajów posiadają właściwości obronne chroniące je przed żerowaniem ślimaków, głównie wysoką zawartość substancji silikonowych.

Uzyskane informacje na temat wysokiej wrażliwości wiechliny łąkowej i kostrzewy czerwonej na żerowanie i uszkodzenia przez $D$. reticulatum i $A$. vulgaris mają duże znaczenie praktyczne. Główną metodą ochrony upraw pszenicy zwyczajnej i innych traw przed ślimakami, jest stosowanie granulowanych przynęt zawierających jako substancje czynne metaldehyd lub fosforan żelaza (Speiser i Kistler 2002; Meredith 2003; Kozłowski 2016). Istotną rolę odgrywają także niektóre zabiegi agrotechniczne, akie jak: płodozmian, podorywka, orka, bronowanie, ugniatanie gleby i inne, które mogą zmniejszyć o połowę liczebność ślimaków w uprawach. Obok metod agrotechnicznych duże znacznie, choć na mniejszą skalę, ma wykorzystanie pasożytniczego nicienia Phasmarhabditis hermaphrodita (Schneider, 1859), stosowanego w formie biopreparatu (Wilson i wsp. 1993). Metody te są jednak niewystarczające, a stosowanie granulowanych moluskocydów może stwarzać znaczne zagrożenie dla fauny pożytecznej występującej w uprawach. Dlatego poszukuje się nowych, bezpiecznych dla środowiska sposobów ograniczania szkód wyrządzanych przez ślimaki. Jednym z nich może być wykorzystanie naturalnych właściwości obronnych roślin, które determinują behawior żerowania ślimaków. Konieczne jest jednak poznanie reakcji poszczególnych gatunków i odmian traw na żerowanie różnych gatunków ślimaków. Wyniki wykonanych doświadczeń są ważnym elementem w opracowaniu strategii ochrony traw przed ślimakami w warunkach produkcyjnych.

\section{Wnioski / Conclusions}

1. Rośliny badanych gatunków traw (w fazie 3-5 liści) wykazały znaczne zróżnicowanie pod względem wielkości uszkodzeń przez ślimaki $A$. vulgaris i $D$. reticulatum.

2. Najmniej podatna na uszkodzenia przez obydwa gatunki ślimaków była pszenica zwyczajna.

3. Wyższą podatność na uszkodzenia przez D. reticulatum wykazały rośliny wiechliny łąkowej, a przez A. vulgaris rośliny kostrzewy czerwonej. Rośliny te powinny być wycofane $\mathrm{z}$ uprawy na polach zasiedlonych przez te gatunki ślimaków.

Badania wykonane w ramach Programu Wieloletniego - Zadanie 1.3. Analiza możliwości ochrony przed agrofagami wybranych rolniczych upraw małoobszarowych. 


\section{Literatura / References}

Barlow S.E., Close A.J., Port G.R. 2013. The acceptability of meadow plants to the slug Deroceras reticulatum and implications for grassland restoration. Annals of Botany 112 (4): 721-730. DOI: 10.1093/aob/mct086.

Briner T., Frank T. 1998. The palatability of 78 wildflower strip plants to the slug Arion lusitanicus. Annals of Applied Biology 133 (1): 123-133. DOI: 10.1111/j.1744-7348.1998.tb05808.x.

Clark S.J., Dodds C.J., Henderson I.F., Martin A.P. 1997. A bioassay for screening materials influencing feeding in the field slug Deroceras reticulatum (Müller) (Mollusca: Pulmonata). Annals of Applied Biology 130 (2): 379-385. DOI: 10.1111/j.1744-7348.1997. tb06841.x.

Dirzo R. 1980. Experimental studies on slug-plant interactions. I. The acceptability of thirty plant species to the slug Agriolimax caruanae. Journal of Ecology 68 (3): 981-998.

Dirzo R., Harper J.L. 1982. Experimental studies on slug-plant interactions. IV. The performance of cyanogenic and acyanogenic morphs of Trifolium repens in the field. Journal of Ecology 70 (1): 119-138. DOI: 10.2307/2259868.

Glen D.M., Moens R. 2002. Agriolimacidae, Arionidae and Milacidae as pests in West European cereals. s. 271-300. W: Molluscs as Crop Pests (G.M. Barker, red.). Landcare Research Hamilton, New Zealand, CABI Publishing, UK, 468 ss.

Grime J.P., MacPherson-Stewart S.F., Dearman R.S. 1968. An investigation of leaf palatability using the snail Cepaea nemoralis L. Journal of Ecology 56 (2): 405-420. DOI: 10.2307/2258241.

Hanley M.E., Fenner M., Edwards P.J. 1995. The effect of seedling age on the likelihood of herbivory by the slug Deroceras reticulatum. Functional Ecology 9 (5): 754-759. DOI: 10.2307/2390248.

Hanley M.E., Fenner M., Whibley H., Darvill B. 2004. Early plant growth: identifying the end point of the seedling phase. New Phytologist 163 (1): 61-66. DOI: 10.1111/j.1469-8137.2004.01094.x.

Hanley M.E., Lamont B.B., Fairbanks M.M., Rafferty C.M. 2007. Plant structural traits and their role in anti-herbivore defence. Perspectives in Plant Ecology, Evolution and Systematics 8 (4): 157-178. DOI: 10.1016/j.ppees.2007.01.001.

Keller M., Kollmann J., Edwards P.J. 1999. Palatability of weeds from different European origins to the slugs Deroceras reticulatum Müller and Arion lusitanicus Mabille. Acta Oecologica 20 (2): 109-118. DOI: 10.1016/S1146-609X(99)80023-X.

Kemp N.J., Newell P.F. 1987. Slug damage to the flag leaves of winter wheat. Journal of Molluscan Studies 53 (1): 109-111. DOI: 10.1093/mollus/53.1.109.

Kozłowski J. 2016. Zagrożenie roślin przez ślimaki i ograniczanie szkód w uprawach rolniczych za pomocą granulowanych moluskocydów. [The threat to plants from slugs and reduction of damage to agricultural crops with the use of granulated molluscicides]. Zagadnienia Doradztwa Rolniczego 4/16 (86): 60-72.

Kozłowski J., Kozłowska M. 2009. Palatability and consumption of 95 species of herbaceous plants and oilseed rape for Arion lusitanicus Mabille, 1868. Journal of Conchology 40 (1): 79-90.

Meredith R.H. 2003. Slug pellets - risks and benefits in perspective. s. 235-242. W: Slug and Snails: Agricultural, Veterinary and Environmental Perspectives (G.B.J. Dussart, red.). British Crop Protection Conference, Symposium Proceedings 88, 2003, Canterbury, Ken, UK, 324 ss.

Mølgaard P. 1986. Food plant preferences by slugs and snails: A simple method to evaluate the relative palatability of the food plants. Biochemical Systematics and Ecology 14 (1): 113-121. DOI: 10.1016/0305-1978(86)90095-5.

South A. 1992. Terrestrial Slugs: Biology, Ecology, and Control. Chapman and Hall, London, 444 ss.

Speiser B., Kistler C. 2002. Field tests with a molluscicide containing iron phosphate. Crop Protection 21 (5): 389-394. DOI: 10.1016/ S0261-2194(01)00120-X.

Speiser B., Rowell-Rahier M. 1991. Effects of food availability, nutritional value, and alkaloids on food choice in the generalist herbivore Arianta arbustorum (Gastropoda: Helicidae). Oikos 62 (3): 306-318. DOI: 10.2307/3545495.

Wilson M.J., Glen D.M., George S.K. 1993. The rhabditid nematode Phasmarhabditis hermaphrodita as a potential biological control agent for slugs. Biocontrol Science and Technology 3 (4): 503-511. DOI: 10.1080/09583159309355306. 